\title{
Volunteering, Governance and Leadership: Reflections on England
}

\author{
Dr. Jason L. Powell (Corresponding author) \\ School of Education and Social Science, University of Central Lancashire \\ Preston, United Kingdom \\ E-mail: Jpowell1@uclan.ac.uk
}

Received: July 16, 2011 Accepted: July 23, 2011 DOI: 10.5296/jpag.v1i1.800

\begin{abstract}
One of the key issues in recent times in England is how voluntary organisations sustain themselves. It is very tempting to view voluntary agencies rather like very fragile "black boxes" adrift on a turbulent sea and at the mercy of powerful social, economic and political pressures. The direction of their journey and their very survival is determined by critical success factors. Although the spate of studies have undoubtedly advanced the state of knowledge about voluntary organisations, we still know very little about the internal composition and operation of the black boxes and even less about the way in which internal factors interact within the external world. The point of this research article is to assess the factors that impinge upon opening and understanding the 'black box' such as governance and quality, leadership, workforce, performance, partnerships and finance and funding. These different critical success factors are part of the inter-locking infrastructure tools of voluntary organisations to perpetuate what works; and what the implications are if some do not work. This requires engagement with research literature on these significant tools of thinking and practice. Arguably the voluntary sectors infrastructure has come under unprecedented scrutiny in the last three to five years, following the British coalition government's (as of 2011) express intention of creating a step change in the support provided to the sector. Lots of searching questions are being asked of infrastructure, not least by the sector itself.
\end{abstract}

Keywords: Governance, Leadership, Volunteer, Performance 


\section{Introduction}

One of the key issues in recent times in England is how voluntary organisations sustain themselves. It is very tempting to view voluntary agencies rather like very fragile "black boxes” adrift on a turbulent sea and at the mercy of powerful social, economic and political pressures. The direction of their journey and their very survival is determined by critical success factors. Although the spate of studies have undoubtedly advanced the state of knowledge about voluntary organisations, we still know very little about the internal composition and operation of the black boxes and even less about the way in which internal factors interact within the external world. The point of this research article is to assess the factors that impinge upon opening and understanding the 'black box' such as governance and quality, leadership, workforce, performance, partnerships and finance and funding. These different critical success factors are part of the inter-locking infrastructure tools of voluntary organisations to perpetuate what works; and what the implications are if some do not work. This requires engagement with research literature on these significant tools of thinking and practice. Arguably the voluntary sectors infrastructure has come under unprecedented scrutiny in the last three to five years, following the British coalition government's express intention of creating a step change in the support provided to the sector. Lots of searching questions are being asked of infrastructure, not least by the sector itself.

\section{Research aims}

1. To identify and present a picture of the conceptual, nature and extent of infrastructure through systematic literature review.

2. To capture organisations perspectives in the systematic review on critical success factors through an in depth exploration of available literature

3. To make research recommendations for strategic action.

\section{Research questions}

1. What are the critical success factors of infrastructural sustainability of organizations?

2. Do support services offer a clear and compelling level of support to voluntary organizations over time?

Many of these research questions concern what infrastructure services are needed, what is provided and how it is coordinated in England. A word of caution however: overall, it is fair to say that the evidence base in relation to the success factors of Voluntary Council Services (VCS) infrastructure is extremely scarce. What there is of an evidence base is fragmented and dissimilar. The evidence that has been included in this assessment tends to derive from single project and programme evaluations of VCS interventions rather than more comprehensive studies of infrastructure as a whole. This also means that it is very difficult to bring evidence together in any cumulative sense to gain an impression of the overall or aggregate impact of VCS infrastructure. Instead the evidence tends to emphasize the benefits of particular approaches, projects or activities. There have been scarce longitudinal research designs, in 
which interventions and their (beneficial) effects can be studied over time; or comparative research or evaluation designs, for example where ostensibly similar interventions or the work of comparable agencies are undertaken in different settings.

Figures indicate the pervasiveness of voluntary sector activity in the UK. Indeed, over $75 \%$ of the UK population is involved in volunteering, either through an organisation or group, or on a more informal basis (Macmillan 2007). Research suggests that some 23 million people volunteer each year, providing a workforce equivalent to 180,000 full-time volunteers. The economic value of formal volunteering in the UK has been estimated at more than $£ 40$ billion per year, or $7.9 \%$ of GDP. For every $£ 1$ of public funding spent to support volunteering, volunteers give $£ 30$ worth of work.

To look at some of these factors in terms of literature base, the following themes are seen as success factors in the sustainability of voluntary organisations. They highlight current albeit extremely scarce research which illuminates the problems and possibilities of building capacity and creating effective infrastructure.

\section{Literature Review}

\subsection{Governance}

There are various definitions of governance in widespread currency can be encapsulated of what Reid and Gibb (2004) state in relation to volunteering:

- A list of duties

- Fulfilling a role (such as custodian or representative);

- Complying with a legal minimum (fulfilling the fiduciary duty);

- Possession of a range of structures and procedures (constitution, board of trustees, written policies and procedures); competences of people and group processes (strategic thinking, group decision-making).

- Leadership as having: vision, strategy, networking skills, create space for others, ask for and listen to others both users and volunteers, motivate and enthuse others (Macmillan et al. 2007).

Governance is essential for organisations to survive. For example, social enterprises need to be sustainable, according to research from the Governance Hub and the Social Enterprise Coalition. The research, undertaken by the Open University into the governance needs of social enterprises, shows that a priority for the social enterprise sector is to strengthen links with governance advisers and consultants working at local and regional levels and provide them with appropriate training and support. The research report, 'For Love and Money: Governance and Social Enterprise' outlines that social enterprises need specific support and information on areas such as overseeing commercial activity and managing business risks, legal and governance structures for trading subsidiaries and small organisations and the governance of multi-organisation partnerships. However, the research also reveals that the governance advice sought by social enterprises share similarities with other community based 
organisations. This includes problems maintaining the balance between social and business goals, getting people with the right skills for boards, involving users in governance issues, and accountability to users.

How is this captured conceptually? The Governance-Human Resource dynamic and the development of organisational strategy are central. Different individuals within an organisation will have significantly different perspectives, based on different histories, cultures, experiences and even goals - particularly in terms of those individuals who collectively make up the governance and human resource systems of voluntary organisations (namely trustees, paid employees and volunteers). These different perspectives have to be integrated and accommodated if effective action is to be taken by all the relevant agents. This has direct implications for the way in which organisations should approach strategy development; employing an approach to strategy development that takes into account different perspectives or different frameworks is not a luxury, it is essential if the proposals that emerge are to have anything approaching widespread support (Mintzberg, et al., 1998). Thus, rigidly separating the strategy-making role as a function of the board of trustees alone is not conducive to the complexity of the internal and external environment in which voluntary organisations operate. The use of such 'command and control' inevitably fails within complex systems and alienates employees by treating them instrumentally (Chapman, 2002). It is likely that, in these circumstances, the command and control culture would serve to undermine the values portrayed by many voluntary organisations. Indeed, Jeavons (1992) urges voluntary sector managers to analyse issues in historical, cultural and moral terms that, he suggests, can sometimes go largely unconsidered in other managerial settings. He emphasises, in particular, the need to consider:

"The ethical integrity of the organisation, the degree to which the organisation's performance actually serves the public good, in the broadest sense of the term, and the degree to which the treatment of employees and volunteers honours the moral and social values that the organisation intends to project in its service work.” (Jeavons, 1992: 416).

Similarly, Cairns et al (2004) suggest that the concept of 'quality' must be associated with organisational development. If we take two direct quotations from Cairns et al. to illustrate this:

"The introduction of a quality system has the potential to make an impact upon internal organisational structures and hence to improve efficiency. It also offers opportunities for organisational growth, increased effectiveness and staff development. In addition, the presence of a quality system is perceived as giving an organisation more legitimacy with external stakeholders” (Cairns et al 2004: 49).

"Quality systems can act as an organisational development tool and provide a common agenda for action, for example: action planning, continuous professional development, team building. Major benefits of having a quality system were seen as including: increased organizational legitimacy, improved reputation and credibility with external stakeholders. The introduction of a system provided the opportunity for an organisation to reflect upon and review their working processes and ways of doing things, this included reflecting upon 
service delivery arrangements" (Cairns et al 2004: 37).

Cairns et al (2004) suggest that external pressure may also come from national infrastructure/membership bodies, some of whom require adoption of their own quality systems as a condition of membership. More usually however, the role of infrastructure bodies seems to be to influence, or encourage, members to use a tailor-made system, but without the element of compulsion. (Cairns et al 2004: 26, emphasis added).

"Some (participants) had sought external help, though mainly with securing advice on aspects of the chosen system rather than with actual implementation. Many study participants had limited knowledge of available resources that might have helped them. This suggests that there is a need, not necessarily for more external resources, but for more information about what is available, and for more help, perhaps from infrastructure bodies, to enable VCOs to access available assistance. Many infrastructure bodies are well placed - with their detailed knowledge of members' objectives and needs - to assist VCOs with selection and introduction of quality systems and, where appropriate, to point them in the direction of relevant external assistance” (Cairns et al 2004: 48).

Research by Reid and Gibb (2004) highlighted the relevance of a grant-making body's capacity building programme. The key research question concerned the extent to which there were sustainable changes to organisational capacity as a result of the input of consultants funded under the programme. The consultancy was often used as a form of expert advice, and as a way of setting priorities for support and intervention, especially where an organisational crisis was apparently looming or underway:

For one charity, lack of focus on their central mission had resulted in their taking on additional work in order to maintain financial security. This led to rapid growth without consideration of the charity's capacity to cope with additional staff, increased regulation and, importantly, their ability to remain financially sustainable at this level.

The Chief Executive felt that the charity was:

“...expanding without any thought for the future - as opportunities arose we grabbed them. We have gone from an organisation that needed not $£ 10,000$ in the bank as reserves, but $£ 200,000$. (Reid and Gibb, 2004)

Often when this was the case, participants did not have clearly defined expectations for the consultancy. This resulted in hopes that were either too expansive, covering an array of practice and strategic issues, or objectives that did not reflect the real needs of the organisation at the time. In such cases consultants tended to play a greater role in helping the charities identify priorities for the consultancy, and to set the objectives for the work. Indeed, this agenda setting stage was frequently perceived as a benefit in itself as the participants learned about the strengths and weaknesses of the organisation. (Reid and Gibb 2004: 8).

Charities were able to use business plans when applying to funding bodies as evidence of their aims, objectives and practices. Strategic plans enabled charities to prioritise their goals and be realistic about what could be achieved within a certain time frame. This was thought 
to have great value as it enabled efforts to be targeted to areas of greatest perceived need (Reid and Gibb 2004: 10).

From research done by Cornforth at Open University Business School (cited in Macmillan, 2007) using postal questionnaires sent to 2797 charities, with a $26 \%$ response rate:

- Only about 35\% of charities provide job descriptions for board members.

- Only 23\% provide some sort of initial training or induction for new board members.

- These percentages are somewhat higher for the larger charities (the range goes from 20\% for the smallest to $77 \%$ for the largest!).

- Average frequency of board meetings was between 5 and 7 a year.

- The size of board in small to medium charities is increasing, but decreasing in larger charities.

- The average size of boards increases with organisation size, going from under 9 in the smallest charities, up to almost 21 for the largest.

For Macmillan (2006) the role of the Board is not necessarily that different from that in business, but some voluntary organisation Boards may, for various reasons, find it difficult to agree clear objectives for the organisation. Some voluntary organisation Boards may be less disciplined in their use of meetings. In voluntary organisations the composition of the Board may be more difficult, or at least slower, to alter than in many for-profit organisations.

Hence, the structures or systems of the governing body are thus in a constant state of interaction and adjustment that requires a reasonable equilibrium or balance (Macmillan, 2007). The promise the threat from the impact upon government funding upon the voluntary sector is that the proportion of funding from government grows and the proportion of private volunteer support declines. The danger here is that non-profit organisations can lose their grassroots contact, as the discipline of seeking charitable contributions and donations of volunteer time from the public has kept voluntary organisations in close contact with their communities and changing community needs. Balance must therefore be maintained between the roots and the governing body if agencies are to avoid severe serious problems. For example, as cited in a case study concerning a single-parents self help group, there was a belief that the problem they were trying to alleviate was one that the government should support which led to applications for substantial funding and the hiring of paid staff. This caused tensions between the different approaches towards responsibility for the problem (implicit policy and welfare accountability) and the consequent human resources required led to the eventual division into association and agency with it's own governing bodies.

\subsection{Performance}

Performance has been identified as being key to the voluntary, community and faith sector being able to build its capacity. One of the keys to this outcome is a focus on performance and quality systems. Macmillan et al. (2007) claim:

"Frontline organisations should be better able to improve the performance of their organisation, make choices about which tools are right for them, and easily access support and advice." 
Macmillan et al. (2007) points to British NAVCA Performance Standards which are:

1. Identifying needs and facilitating improvement in service provision

2. Assisting local organisations to function more effectively

3. Facilitating effective communication, networking and collaboration amongst local groups

4. Enabling the representation of the diverse views of the local sector to external bodies

5. Enhancing the sector's role as an integral part of local planning and policy-making

One dimension of sustainability that has and continues to preoccupy voluntary organisations is mobilising resources for their performativity. Whilst understandable in the current 2010 economic climate of the 'Global Credit Crunch', the fixation of some organisations which solely equates obtaining income with sustainability is dangerous if an organisation wishes to be viable, autonomous and civic (Fowler, 2000). In developing strategies, it is important for voluntary organisations consciously to consider and challenge the way in which different decisions about organisational identity and role in society lead to different strategic priorities in fund-raising. From a sustainability perspective, reducing resource vulnerability through the diversification of funding sources is an important task, but voluntary organisations are vulnerable in another way as well. Strategic choices in terms of resources have implications beyond their reliability, they affect what the organisation stands for.

The growing prominence given to trustees' strategy-making role occurs against a backdrop of an "increasingly professionalized and managerialist voluntary sector" (Harrow \& Palmer, 1998: 171). As such trustees have experienced a significant increase in advice appertaining to how to perform effectively, behave legally, and provide leadership for their organisation (Harris 1991; Quint, 1994; Hind, 1995). Much of the literature on strategic management and planning in a voluntary sector context began with Bryson's (1988) work, which places trustees as the final decision makers within a voluntary organisation who are competent to work with and, if necessary, prepared to change a voluntary organisation's planning culture.

Buse (1993 pp.43-44) argues that the important function of trustees is:

"not to manage process but to manage outcome, with the trustees guardians of the values of the charity, and the values driven by the charity's planning”.

The Scottish Government (2006) states that performance management of the sector is vital in order to retain the confidence of the public. Not only is public money on the line, but statutory responsibility still remains with government, which makes assessment of how it's chosen vehicles perform an imperative. The effectiveness of the sector, in delivery of services, is measured by the sponsoring policy teams. It is right that those who commission services determine the correct objectives and design performance management systems accordingly. Much of the performance management function is undertaken within local government. Performance management tools vary, but include targets, conditions of grants, performance indicators, contacts and annual reports. 
Infrastructure interventions can often take the form of expert advice and guidance, especially given the complexities of the performing environment for 'frontline' voluntary organisations. Infrastructure agencies can be a resource for the sector as a whole, a repository of specialist knowledge and experience. Between 2000 and 2002, Osborne et al. undertook a comparative study of community involvement in rural regeneration partnerships (CIRRP) in localities in England, Northern Ireland and Scotland, funded by the Joseph Rowntree Foundation. The study came to unequivocal conclusions about the beneficial role of local VCS infrastructure in promoting and supporting CIRRP:

The overwhelming opinion in this study was that infrastructure was essential to the success of CIRRP. It facilitated the links between the different structural levels of regeneration partnerships, provided technical assistance and expertise, supported small scale funding schemes which built local expertise and confidence and which helped develop the capacity of individuals and groups to participate in regeneration (Osborne et al 2002: 24). It is clear from this study that strong infrastructure is essential to the promotion, development and sustenance of CIRRP (Osborne et al 2002: 40)

Osborne cites two overarching roles for VCS intermediary organizations:

- Horizontal capacity building: building the capacity of communities across rural areas to develop and participate in projects and partnerships to regenerate their communities

- Vertical capacity building: building the capacity of communities and community activists to participate in the strategic level of partnerships (Osborne et al 2002: 29)

Osborne (2002) et al. have argued that it was the effectiveness of these intermediary bodies which determined the success, or otherwise, of CIRRP in all three nations. The key tasks that they undertake include promoting communication, both with the community in an inclusive way and between the community and strategic levels of the partnership; procuring resources to fund small scale funding schemes that will work to encourage community involvement; ensuring the availability of trained facilitators to support community involvement - both the models of the professional development worker and the enthusiastic 'animateur' have their advantages, and neither should be seen to preclude the other; feeding key information both to communities about regeneration initiatives and to strategic agencies about needs; providing infrastructure resources to support communities, including technical assistance and professional advice; enabling training in skills for community members, both about regeneration and about the skills of partnership working, at both the community and strategic level (Osborne et al 2002: 29-30)

For Osborne and colleagues, the significance of local VCS infrastructure is clear. It is not so much that it tends to do a good job in fulfilling its functions, or is well appreciated by its users and members, but rather that community performance in regeneration relies upon effective and strong local VCS infrastructure. However, in so far as public policy continues to prioritise community involvement, it would seem from this research that VCS infrastructure not only has a central role to play, but would seem to be a critical success factor in performance of local infrastructure organisations. 


\subsection{Finance}

Finance is a key issue for all VCS organisations, particularly given the current funding climate, and the culture shift in the way in which organisations are funded. The Charities Commission Register (2007) includes 190,541 charities and suggests that they have combined annual income of $£ 44.552$ billion. These illustrate the necessity to sustain an organization in terms of its resources. Morgan (2006) suggests the long term sustainability of an organisation can only be assessed through longitudinal studies over many years. In practice what is likely to be important is to be able to assess the likely sustainability of an organisation at $a$ particular point in time.

Provided an organisation has a long term mission, a possible criterion would be that in order to be classed as financially sustainable at the current time, its leadership (trustees/senior staff) must be:

-certain (or 99\% certain) that it has the resources to continue its core work for at least 12 months;

-fairly confident (at least 75\% certain) that it can continue its core work for at least 24 months.

For income to be classified as contributing to the core in this way, it should preferably be unrestricted (See Charity Commission Web Site 2010), or, at the very least, if restricted it must be restricted to functions or activities which all agree are central core functions of the organisation.

In a smaller organisation both roles may be done by the same person, or in a very small organisation, may fall to trustees - but the key thing is that, whatever the size, there are clearly identified people with the relevant skills (Morgan, 2006). These importance of these aspects of financial management are clearly documented in various works of voluntary sector finance and accounting but is it interesting that such texts rarely use the term "sustainability". Rather, the focus of financial management is presented mainly in terms of stewardship and accountability for charitable funds, or broader notions of voluntary sector effectiveness.

However, Morgan (2006) suggests that financial management is not simply an operational issue. To be financially sustainable, a voluntary organisation requires appropriate arrangements for financial governance so that the trustees are properly in control of the finances, and are properly involved in all financial decisions. Morgan (2006) lists the following three issues:

1. Financial oversight. Amongst other things, the trustees need arrangements to monitor the work of finance staff to be sure that controls are being followed and the "finance manager" needs to have the confidence/authority to communicate directly with the trustees and to implement trustees policy.

2. Appropriate financial decision making - so that trustees will take action on the basis of financial information, in particular to take remedial action in good time when expenditure is likely to exceed income. (It is not sufficient to do this in relation to 
the organisation as a whole - decisions need to be made in relation to individual funds - especially the general fund in terms of ability to sustain the core work.)

3. Proper financial accountability to external parties - e.g. compliance with legal requirements on production of annual reports and accounts, audit or independent examination, and filing of accounts on time.

Resources have the potential to steer organisations and how they raise the resources they need has a strong influence on what an organisation is and what it can be. From a sustainability perspective, reducing resource vulnerability through the diversification of funding sources is recognised as an important task; $69 \%$ of survey respondents felt that organisations which do not have a diverse range of funding streams are at risk of sacrificing their independence. But voluntary organisations are vulnerable in another way as well. Strategic choices in terms of resources have implications beyond their reliability, they affect what the organisation stands for, which equates to a second task of protecting its mission and identity (Hailey \& James, 2004) - a key role of the board of trustees (Charity Commission, 2007).

Many aspects of the role of intermediary or infrastructure interventions encompass what Osborne (2002) has described as a 'catalytic approach' to supporting voluntary and community action. By undertaking one piece of work (such as helping a local group put together a successful funding bid) it contributes to another objective also (such as building the capacity of community groups to make such funding bids in their own right in the future) (Osborne et al 2002: 29).

An example of multiple benefits being realised at different levels from the same programme is provided by a fundraising training project in the BME voluntary and community sector in London. The final evaluation report (LDA 2005) looks at 'impacts' at three levels: for training participants, for participating organisations, and for the sector as a whole.

1. Impact on participants, such as enhanced understanding of fundraising in context; increased confidence, improved access to networks and enhanced status.

In the first place, the project did a great deal more than equip participants with knowledge and skills; it enabled them 'to look at fundraising in a new light'. They had gained a better understanding of the process of fundraising, of the environment in which it took place and of the relationship of fundraising activities to wider issues of organisational effectiveness. There was a consensus that trainees had gained a great deal more confidence in their ability to undertake the fundraising role. These two key impacts had enabled them to develop a 'more strategic' approach to the role and one which was 'better organised' and 'more professional'. Other impacts mentioned by some participants were improved access to networks and enhanced professional status - they received 'more recognition' within their organisations and some felt that their career prospects had been enhanced. (LDA 2005: 26)

2. Impact on participating organisations, such as the extent to which it enabled participating organisations to access more funds from a wider range of sources (for which it was too early to judge) and the development of a more strategic approach to fundraising: We also found, however, some evidence of organisations which had developed better ways of conducting 
research into sources of funding and had made applications to a broader range of funding bodies. More commonly, participating organisations had laid some of the foundations for a more effective approach to fundraising. More than half of those who responded to the survey had made progress in developing a fundraising strategy or a business plan - and sometimes both. Some participants had successfully involved trustees and other staff in subcommittees or working parties devoted to fundraising and had provided them with some basic training. In a number of cases, fundraising had become a higher priority for the organisation and been increasingly recognized as a core function. (LDA 2005: 26)

3. Wider impact on the BME voluntary and community sector:

As well as 'cascading' the knowledge and expertise provided by the training programme within the organisations participating in the project, the partners intended it to have a wider impact in the faith group voluntary and community sector as a whole. While it is again very early in the life of the project to expect to find evidence of that kind of impact, it was clear from the case studies that participants had provided advice and support on fundraising and organizational development to a number of other organizations

In some cases, the mechanism for this was the existing involvement of the individual with other agencies as a trustee. In at least one other case, the participating organisation had a capacity building role within a sub sector of the faith sector and could incorporate the new knowledge in its ongoing work. Elsewhere, the project stimulated a specific set of responses; one of the participants who worked for a Tamil organisation in south London brought together people from other organisations in the area to disseminate what he had learned about the need to develop a strategy and take a longer term view of fundraising (LDA 2005: 27). Yet, despite this point, the literature on BME infrastructure is very poor.

Rosewarne's small evaluation (2003) for South Yorkshire Funding Advice Bureau (SYFAB) of a funding training programme delivered to groups in the coalfields areas of South Yorkshire concludes that:

The SRB funding for a period of three years enabled SYFAB to provide an extensive training programme to a large number of voluntary and community groups in the South Yorkshire Coalfields area. The vast majority of groups benefiting from this training would not otherwise have been able to access such extensive, good quality training and of such variety. In turn over $£ 4,000,000$ has been brought into the area in the form of grants to groups who accessed the training. Whilst not claiming that this was all entirely due to the training it clearly played a substantial role in helping groups bring in this money (Rosewarne 2003: 13).

The evidence for this comes from two sources. Firstly, feedback from training participants notes that 70 respondents (87\%) had been involved in making funding applications since attending the course, of which 67 bids had been successful, raising a total of $£ 1,437,720$. Secondly the evaluation involved a "detailed search of grants awarded by four key funders [Awards for All, Community Fund, Coalfields Regeneration Trust and Local Network Fund]....showing] that 81 groups who had participated in the accredited training course had between them successfully raised £3,213,667 (Rosewarne 2003: 7). 
The evaluation of the fundraising training project in the BME voluntary and community sector in London makes the following overall comment on the impact of the programme: The evidence is that the individuals who took part in the programme gained a variety of benefits from their involvement. This not only gave them enhanced skills and confidence with which to tackle the challenge of fundraising but also enabled them to have an impact on way their own organisations and - to a lesser extent - other BME organizations went about their business. (LDA 2005: 30, emphasis added). This is echoed by Rosewarne's small evaluation of a funding training programme in South Yorkshire, where one participant commented that "The course gave me confidence in tackling funding applications with very little supervision.” (Rosewarne 2003: 5).

Reid and Gibb (2004) note how individual consultancy helped change the way organisations went about raising funds: Change in approaches to fundraising was evident, although it was not possible to tell whether the techniques adopted were making a difference. Fundraising techniques that were being put into practice included use of a fundraising calendar which listed the submission dates of the most relevant grant-making bodies. Perhaps more importantly, interviewees felt they had more awareness of how to approach funders with realistic aims, and this resulted in increased confidence in their approach to fundraising. (Reid and Gibb 2004: 10).

Voluntary organisations have different problems and considerations in financial controls and accounting. In particular, voluntary organisations are more likely than businesses to view deficits as often desirable and large reserves as undesirable. Systems for financial control may be complicated by the amount of cash handled, the number of branch accounts, and the cultural emphasis on trusting staff and volunteers.

In addition, and for various reasons, keeping income and expenditure balanced may be more difficult in voluntary organisations, and there may be a different attitude to the role of budgets in that process. In relation to outputs, there are peculiar difficulties in performance measurement and quality control in voluntary organisations which are less commonly found in for-profit organisations. One difficulty was the 'anti measurement' ethos reported in some voluntary organisations.

There are also issues of human resources. Indeed, a source of strength consists of human resources at the disposal of the organisation. These resources comprise of paid and voluntary staff undertaking operational and supporting work. When the association employs paid staff to undertake its operational activities this represents a move into the bureaucratic territory of agency status. The problem here is that administration work threatens to dominate substantive work in the voluntary sector. Following the patterns of government agencies to provide funds, administrative work is being increasingly carried out by specialist personnel staff that demand and deserve a substantial salary. The bureaucratisation of the voluntary sector for some has thus been a welcome development by replacing amateurism and crisis management with professionalism and planning in order to develop sound management practices. Bureaucratisation can therefore be seen as an essential condition of survival (Deakin, 2002). However, on the other hand bureaucratisation can also have implications: 
- Voluntary sectors in the past had been lean on administration allowing them to place most of their money into facilitating the rapid and flexible responses to challenging social conditions and needs.

- Necessary administration work has often been carried out by volunteers or by efforts of professionals in the community.

- When voluntary organisations become more like businesses government these qualities are at peril and must therefore take a hard look at the implications of government funding and their role within society.

- Citizens of the community/volunteers can be weary of voluntary agencies that spend a high proportion of funds on administrative costs.

The irony here is that the government often fails to cover the full cost of it's administrative work necessitated by grants and contracts, thus the balance must come from charitable contributions especially pushed more politically by government in an economic climate of cuts in public expenditure.

\subsection{Workforce}

Workforce development is seen as a key area in requiring capacity building within the VCS. In order to be in a position to better deliver services, the workforce of the voluntary community and faith sector must develop its workforce's capacity.

New research from the Workforce Hub and NCVO has revealed a significant growth in the VCS workforce in the last decade. This rate of growth has in fact been at a higher rate than the public and private sectors. However, the 2007 Voluntary Sector Skills Survey published in tandem with this reveals a number of challenges for the sector's employers. One-quarter of organisations report hard to fill vacancies within their organisation and skills gaps in IT, legal knowledge and fundraising. As the number of paid employees in the voluntary sector has increased, so has interest in the role of the VCS as an employer and the social and economic significance of this role. Another contributory factor to the problem has been the rapid growth in size of the sector over the past decade. Recent years have seen an increasing emphasis on the VCS to be a deliverer of public services, changing characteristics and working patterns of the sector's employees and the increased professionalisation of the sector, which all brings both challenges and opportunities for the VCS. 40\% of VCOs interviewed anticipate that recruitment will get more difficult over the next three years.

The UK Voluntary Sector Workforce Almanac (2007) has picked up on this point. There is an increased professionalisation of the sector - One-third of VCS employees (33\%) have a degree or equivalent qualification. Between 1996 and 2005 this has increased by 43\%. (For information related to this professionalisation - see 'professionalisation of volunteering'.)

-A more female workforce - Over two-thirds of the VCS workforce is female (69\%), similar to the public sector (64\%) but much higher than the private sector (40\%).

-A higher proportion of part-time workers - Part-time employees account for 39\% of 
voluntary and community sector employment - higher than in the public and private sectors (29\% and $23 \%$ respectively).

-A bigger deliverer of public services - There has been a huge increase (86\%) in the number of people working in social care, from 149,000 in 1996 to 277,000 in 2005. Social care now accounts for $54 \%$ of the VCS' employees. (See 'bringing markets into public services'.)

-A higher proportion of disabled staff - Nearly one in five people (18\%) working in the -VCS has a disability, higher than the public (14\%) and private sectors (13\%).

-Smaller workplaces - One-third of VCS workers (32\%) are employed in workplaces with less than ten employees. This is vastly different to both the private (25\%) and public sectors $(8 \%)$.

-Hard to fill vacancies - Recruitment problems are evident across the sector with $25 \%$ of employers reporting hard to fill vacancies, particularly within youth work, social care and health care.

-Under skilled staff - Around 30\% of employers reported under-skilled staff. Small organisations are more likely to report skills gaps. This is leading to an increase in the workload of other employees. $25 \%$ use volunteers to cover the work, particularly within smaller organisations.

-Lack of funding for training - 50\% identified that skills gaps were caused by a lack of time and funding for training within their organisation. All these factors make it imperative for employers to concentrate on the management of human resources in terms of workforce development. However with planning and foresight, the growth already experienced will lead to a professional and thriving sector.

The workforce of the voluntary sector (VS) comprises two main groups: paid staff and volunteers. The UK Voluntary Sector Skills Survey estimates that there are 559,000 people employed in VS organisations of two or more paid staff in England. This estimate is higher than Labour Force Survey (LFS) estimates, which suggest there are 518,000 paid employees within the English voluntary sector. This may be because UK Voluntary Skills Survey (VSS 2007) uses an employer-based measure, and the LFS uses an employee-based measure. Within the UK as a whole, the LFS estimates that there are 611,000 paid employees in the sector, accounting for $2.2 \%$ of the UK workforce. The UK VS has grown by nearly 80,000 employees (14.9\%) since 2000. The growth in the sector is linked to almost 20 years of public service delivery being contracted out by central and local government agencies to the sector (VSS 2007). There are a relatively high number of part-time and female employees within the sector. Within the UK, 39\% of VS employees are part-time and 69\% are female. This has particular implications for employment policy and practice. Alongside the 611,000 paid employees within the UK VS, an estimated 14.1 million people volunteer formally once a month (VSS 2007).

The 2007 Voluntary Sector Skills (VSS) Survey highlights that part-time staff, however, have a different proportion of men/women to that of the full-time workforce. Men are much more 
likely to work full-time rather than part-time in the voluntary sector, with $79 \%$ of men employed full-time. In contrast, only $54 \%$ of women employed in the voluntary sector work full-time. On the one hand it is good news for the sector that so many women in the voluntary sector work part-time and do not want a full-time job, as it shows that they really value the opportunity to work part-time hours. On the other hand, $17 \%$ of male part-time voluntary sector employees would like a full-time job but cannot find one - a figure that has, encouragingly, decreased between 1996 and 2005. These findings show that both full-time and part-time employment opportunities are valued within the sector. The opportunity to work flexibly can improve people's ability to balance home and work responsibilities. Figures from the Office for National Statistics (ONS) show women were more likely than men to have some form of flexible working arrangement. Just over one in four women used a flexible working pattern compared to around one in five men (VSS 2007).

At the same time, there are implications of skill shortages. Futureskills 2003 identified skills shortages as a major cause of unfilled vacancies. The UK Voluntary Sector Workforce Almanac (2007) claims nearly a quarter of employers cite a lack of specialist skills in applicants as the main reason for their hard to fill vacancies (24\%). There are therefore a large number of potential applicants who could benefit from specialist training. Applicants' lack of experience is also identified as a reason for hard to fill vacancies by just under a quarter of employers (24\%). Less of an issue is a lack of qualifications; however, $13 \%$ of employers report it as a reason for their hard to fill vacancies (VSS 2007).

Other research we have conducted confirms the large number of highly qualified VS employees, one-third of VS employees hold a degree or equivalent qualification and only 6\% of VS employees have no qualifications at all.

A combination of poor job descriptions and inadequate recruitment practices mean that potential applicants choose not to apply and the ones that do apply do not have the opportunity to shine during the interview. It may also be that employers have unrealistic expectations of the applicants.

To address this, Shortcut (2006), which is a piece of research commissioned by Red Cross, Help the Aged, and CSV, found the following aspects are worth highlighting when recruiting volunteers:

- the opportunity to really make a difference to someone’s life, perhaps illustrated by case studies

- the chance to use spare time productively

- the chance to be flexible

- the support and back-up available to volunteers as part of a supportive team

- where possible, commitment levels to suit volunteers, including the time limited nature of some work

- volunteers are likely to stay for at least a couple of years and usually only leave if 
their personal circumstances

\subsection{Partnerships}

The focus on partnerships in recent years is an important dimension in the voluntary sector working with other agencies. For example, the Community Involvement in Rural Regeneration Partnerships (CIRRP) study is an interesting exemplar because it examined partnership activity and the role of VCS infrastructure in three different case study settings: Devon, County Antrim and Dumfries and Galloway. One study that has been able to assess longer term change is Pearson's (2003) follow up study of the Community Fund's one year 'Brass for Barnsley' initiative. The research was carried out some three years after the initiative had come to an end, and followed an interim evaluation focusing more on issues of implementation and initial impact. The key change noted over time was the degree of co-ordination found in the local voluntary and community sector, and the evaluation argues that this was attributable in part to the impetus in the original programme.

The report argues that Brass for Barnsley was able to act not only as a dedicated area-based funding programme, but as a catalyst for change:

The baseline study carried out for the first BfB evaluation in 1999 identified a voluntary and community sector (VCS) in Barnsley that was characterised by fragmented infrastructural support, with limited partnership working and co-operation, either within the sector or between the voluntary and statutory sectors.

Pearson (2003) found a greater degree of partnership working between voluntary sector infrastructure organisations (VSIOs) in Barnsley; improved relationships between the VCS and Barnsley Metropolitan Borough Council (BMBC); and improved relationships between VSIOs and voluntary and community groups (Pearson 2003:7).

The key lesson emerging from the long term evaluation of $\mathrm{BfB}$ is that there are enormous potential benefits to be gained from the [Community Fund] working in partnership with VSIOs, other funders and statutory organisations in priority areas. In both Barnsley and Rotherham the CF has been central in the establishment of networks which have impacted substantially on the VCS. These networks have continued to provide the CF with opportunities for local engagement. Critical factors in the success of networks include bringing together all key agencies, and maintaining flexibility to reflect local circumstances. (Pearson 2003: 21).

In particular, the initiative led to the establishment of a cross-sectoral network around funding issues for the VCS: Respondents highlighted the work of the Creating Self Reliance (CSR) network as a critical factor in improved relations between and amongst VSIOs and the statutory sector. BfB contributed to a step change in the relationship between the VCS and Barnsley MBC. The benefits of bringing together the VCS, funders and the statutory sector to work together had been learned from the experience of BfB in Barnsley and have resulted in the development of the Rotherham Funding Group. Key factors contributing to the success, and sustainability, of these networks included: 
-bringing together a range of VSIOs to work collaboratively

-the inclusion of funders - the CF and others

-developing, or building on, relationships between the VSC and the local authority

-identifying a small number of key individuals to 'champion' activities

-focusing on strategic issues for the sector, as well as on local development needs

-reflecting local circumstances (Pearson 2003: ii-iii)

In particular, respondents in this study noted how the 'Creating Self-Reliance' network had led to a greater sense of strategic coordination locally in the VCS. Pearson (2003) suggests that impact of the CSR have included: improved communication at all levels of the sector; better dissemination of information to voluntary and community groups; and a clearer strategic vision for the voluntary and community sector. The strategy developed through the future visioning event has been developed and embedded into the Borough's Community Plan and is now the community development strategy for Barnsley.

On a different note yet still focusing on 'working with others'; working with consultants has been highlighted as a key issue. Reid and Gibb’s (2004) study of the use of consultants noted three different approaches, with different advantages and disadvantages:

(i) facilitation, which "aimed to empower the organisation to achieve its own goals [and] tended to involve group strategies for brainstorming and reflection on current practice";

(ii) mentoring, which "centred around offering practical guidance to individuals, and supplying feedback on actions subsequently taken. This approach tended to involve key staff members, who often held much of the expertise and knowledge relevant to the area of consultancy already. This practice was successful in terms of the development of expertise for those individuals who worked closely with the consultants....However, there was little evidence of these key individuals disseminating what they had learnt throughout the organisation so that new knowledge/skills might be retained. There is a danger that this expertise may be lost to the organisation on the departure of these key individuals" and

(iii) training, which: "involved knowledge transfer which stopped short of providing practical assistance. This approach was more conducive to dissemination throughout the charity. An example of this was a training day organised for managers of branches of one charity, focusing on developing fundraising strategies. In this way, the consultant passed on information throughout the whole structure of the organisation, but the potential for depth of learning was not as great” (Reid and Gibb 2004: 9) 


\subsection{Faith-based organisations}

These organisations form a large section of the Voluntary, Community and Faith Sector. They are, however, often overlooked or misunderstood. This literature review has found extremely scarce (putting it mildly) range of writings on the Black and minority ethnic voluntary sector in this country. A Black and minority ethnic organisation (BME) is defined as:

“....an organisation which is led and managed mainly or entirely by Black or other minority ethnic people, which serves mainly Black or minority ethnic people.” (Home Office 1999: 11).

There is currently very little literature that focuses on BME as a field of study in its own right. Of course, there is a lot of literature that implicates the role of the BME sector and much of this can be found in academic literature and research reports on the Black and minority ethnic communities. What was found is that the literature that does exist mainly comprises of two types:

1. Strategy and policy intention statements by bodies such as Government and national BME organisations;

2. Research, consultative or policy reports issued by bodies such as local BME sector consortiums and individual BME organisations.

\section{Research implications}

There is a clearly a need for more research on the question of the benefits of VCS infrastructure for the BME sector. But there is also a need for better co-ordinated research, for research that fills gaps, or takes up unresolved puzzles, or takes off from where existing research stops. Coupled with this, dissemination amongst BME practitioners, policy makers and researchers of existing research on VCS infrastructure requires some considerable attention. New approaches to managing BME voluntary organisations emphasising local autonomy, recognition of cultural differences, participation, empowerment, equality, trust and flexibility - are all important but lack of longitudinal work displays an almost empty literature.

One key area that is yet to be studied is the potential differential effects on urban and rural infrastructure. Policy research in the UK is often criticized for having an urban bias and failing to take account of the different dynamics of rural communities especially the notion of distance decay (Reid and Gibb 2004); a phenomena where the availability of and access to community based services decreases the further one is from large urban areas. Older people are also disproportionately represented in rural areas (Powell 2011). In addition, concerns have been raised about the availability of volunteers to provide services as well as anxiety of social exclusion and vulnerability. 


\section{Conclusion}

Voluntary organisations provide valuable lessons in the art of making infrastructure practices work, as well as illustrating some of the tensions and dilemmas generated in building up capacity and understanding the black box, the internal composition of what works most effectively. Local infrastructure organisations have variations in terms of current research on critical success factors. The future task is to understand these critical success factors balanced by more qualitative narrative; in order to see how it corresponds to the literature or subverts such arguments. There is a need to mapping the causes and consequences of organisational change in a complex world and preparing for future change in terms of strengthening the resilience of community, charitable, and voluntary organisations through promotion of deeper collaboration in the face of adverse global economic factors; in dissecting 'governance' processes which have proved inadequate in the face of the spiralling complexity of financial innovation in the current economic market through learning from each others 'black boxes' opens up possibilities of sustainment and capacity building of organisations of the third sector.

\section{References}

Big Lottery Fund (2006) BASIS (Building and Sustaining Infrastructure Services) Programme Guidance Notes Stage One March 2006

Biggs, S and Powell, JL (2003) 'Older People and Family in the United Kingdom'. In Bengston, V. and Lowenstein, A. Global Aging. New York: Aldine de Gruyter

Billis, D (1991) The Roots of Voluntary Agencies: A Question of Choice Non Profit and Voluntary Sector Quarterly 20 (57)

Bryson, J. (1988). Strategic Planning and Non-Profit Organisations: A guide to strengthening and sustaining organisational achievement. San Francisco, CA: Jossey-Bass.

Buse, R. (1993). Strategic Planning in the Charity Context. In Charity Managers and Charity Trustees: Meeting the challenges of the 1990s (edited by J. Harrow, A. Hind, \& P. Palmer). London: National Council for Voluntary Organisations Publications.

Cairns, B (et al.) (2004) 'So Many Tiers, So Many Agendas, So Many Pots of Money' The Challenge of English Regionalization for Voluntary and Community Organizations'. Social Policy and Administration 38 (5), 525-540

Capacitybuilders (2006) Destination 2014: Investing in Change: A draft for consultation Birmingham, Capacitybuilders, December 2006

Capacitybuilders (2006) Fit for Growth: Building sustainable voluntary and community organisations. Capacitybuilders’Strategy 2006 Birmingham, Capacitybuilders, May 2006

Chapman, J. (2002). System Failure. London: Demos.

Charity Commission (2007). The Essential Trustee: What you need to know. London: Charity Commission. 
Darwin, J., Johnson, P. \& McAuley, J. (2002). Developing Strategies for Change. Harlow, England: FT Prentice Hall.

Forrester, J. (1989). Planning in the Face of Power. Berkely, CA: University of California Press.

Fowler, A. (2000). The Virtuous Spiral: A guide to sustainability for NGOs in international development. London: Earthscan Publications.

Garvey, R. \& Williamson, B. (2002). Beyond Knowledge Management: Dialogue, creativity and the corporate curriculum. Essex: Prentice Hall.

Hailey, J. \& James, R. (2004).'Trees Die From the Top: International Perspectives on NGO Leadership Development’. Voluntas, 15 (4), 343-353.

Harris, M. (1991). Exploring the Role of Voluntary Management Committees, Working Paper 10. London: Centre for Voluntary Organisation, London School of Economics and Political Science.

Harrow, J. \& Palmer, P. (1998). Reassessing Charity Trusteeship in Britain? Toward Conservatism, Not change. Voluntas: International Journal of Voluntary and Nonprofit Organisations, 9 (2), 171-185.

Hind, A. (1995). The Governance and Management of Charities. Barnet: Voluntary Sector Press.

Home Office (2004) ChangeUp: Capacity Building and Infrastructure Framework London: Home Office

Jeavons, T. H. (1992). When the management is the message: Relating values to management practice in non-profit organisations. Nonprofit Management \& Leadership, 2(4), 403-417.

London Development Agency (2005) Partners in Training: An evaluation of the Black and Minority Ethnic Fundraising Training Initiative London: London Development Agency)

Macmillan, R (2006) A Rapid Evidence Assessment of the Benefits of Voluntary and Community Sector Infrastructure Report for the Infrastructure National Partnership, Sheffield, Sheffield Hallam University

Macmillan, R. (et al.) (2007). Building effective local VCS infrastructure: the characteristics of successful support for the local voluntary and community sector, Sheffield: Sheffield Hallam University

Mintzberg, H., Ahlstrand, B. \& Lampel, J. (1998). Strategy Safari: The complete guide through the wilds of strategic management. New York: FT Prentice Hall.

Morgan, G, (2002). The Charity Treasurer's Handbook: An Introduction to Voluntary Sector Finance and Accounting (London: Directory of Social Change). 
Morgan, G. (2007). Financial Sustainability in Voluntary Organisations: A Review of Concepts and Literature, Sheffield Hallam University: CRESR

NCVO (2007). The Sustainability Funding Project (www.ncvo-vol.org.uk/sfp)

Osborne, SP (1999) Promoting Local Voluntary and Community Action: the role of Local Development Agencies York, York Publishing Services/Joseph Rowntree Foundation

Osborne, SP., Beattie, R. and Williamson, P. (2002) Community involvement in rural regeneration partnerships in the UK: Key issues from a three nation study. Regional Studies 36(9), 1083- 1092

Pearson, S. (2003) Evaluation of the Long Term Impact of the Community Fund's 'Brass for Barnsley' Initiative, (London, Community Fund) Final Report, October 2003

Plowden,W.(2003), The Compact: Attempts to Regulate Relationships between Government and Voluntary Sector in England. Non-Profit and Voluntary Sector Quarterly (2003)

Reid, M and Gibb, K. (2004) “Capacity Building' in the third sector and the use of independent consultants: evidence from Scotland' A paper presented at the ISTR $6^{\text {th }}$ International Conference, Toronto, July 2004

Rosenbaum, N (1981), Government Funding and Voluntary Sector: Impacts and Options. Non Profit and Voluntary Sector Quarterly1981; 10; 82

Rosewarne, A. (2003) South Yorkshire Funding Advice Bureau: Evaluation of the Bureau's SRB funded Training Programme, (Sheffield, SYFAB)

Schön, D. A. \& Rein, M. (1994). Frame Reflection. New York: Basic Books

Shortcut Briefing Paper 4. CVS/Help the Aged/Red Cross (2006)

Quint, F. (1994). Running a Charity. Bristol: Jordans.

The UK Voluntary Sector Workforce Almanac (2007)

The Voluntary Sector Skills Survey (2007) 